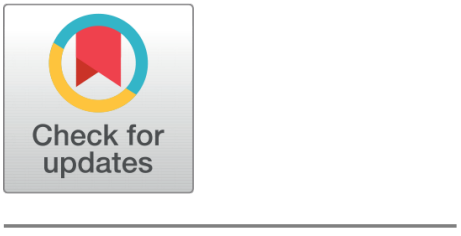

OPEN ACCESS

Received: 23.01.2021

Accepted: 06.04.2021

Published: 29.04.2021

Citation: Guido RM, Kalaw J (2021) Presence of Light Pollution as a Latent Anthropogenic Influence of Bat Dispersal in Mindanao, Philippines. Indian Journal of Science and Technology 14(15): 1177-1183. https://doi.org/ 10.17485/IJST/V14i15.123

* Corresponding author.

Tel: +63-927-886-9138

rmdguido@rtu.edu.ph

Funding: None

Competing Interests: None

Copyright: @ 2021 Guido \& Kalaw. This is an open access article distributed under the terms of the Creative Commons Attribution License, which permits unrestricted use, distribution, and reproduction in any medium, provided the original author and source are credited.

Published By Indian Society for Education and Environment (iSee)

ISSN

Print: 0974-6846

Electronic: 0974-5645

\section{Presence of Light Pollution as a Latent Anthropogenic Influence of Bat Dispersal in Mindanao, Philippines}

\author{
R M Guido ${ }^{1,2 *}$, J Kalaw ${ }^{1,2}$ \\ 1 Associate Professor, Center for Astronomy Research and Development, Rizal Technological \\ University, Mandaluyong City, 1550, Philippines \\ 2 Department of Earth and Space Sciences, Rizal Technological University, Mandaluyong City, \\ 1550, Philippines. Tel.: +63-927-886-9138
}

\section{Abstract}

Background/Objectives: The study aimed to determine the extent of the presence of light pollution dispersal in Mindanao, Philippines that influences bat dispersal. Methods/Statistical analysis: Satellite imagery and radiance data $\left(10^{-9} \mathrm{~W} / \mathrm{cm}^{2 *} \mathrm{sr}\right)$ from Visible Infrared Imaging Radiometer Suite (VIIRS) were processed using different python codes to identify the pixel count as the extent of light pollution radiance in Mindanao, Philippines from 2012 to 2019. The VIIRS was set at an overlay of 60 transparency levels thru Sky Quality Meter (SQM) at 85 transparency levels for a hybrid base map at an altitude of $100 \mathrm{~km}$ to cover the island of Mindanao. Findings: The increase and spread of pixel count as light pollution in the region from 2012 to 2019 have shown significant expanse in the region. Major cities were found to be predominating evidence of light pollution as it stretches from town to town with intensifying pixel counts year by year. Having a strong positive linear relationship as identified $\mathrm{R}^{2}$ value and the increase of pixel counts throughout the parameters of the study is also anticipated that the site shows possible progress towards the community. It shows the increasing radiance and the extreme dispersion on the amount of light being emitted from the ground is critical towards bats dispersion throughout the region. Novelty/Applications: This study fosters evidence the increasing light pollution in a bat-prone region might cause possible bat dispersal related to BtCoV and/or any disease-carrying species present in Mindanao, Philippines.

Keywords: Light Pollution; Bat Dispersal; Mindanao; Philippines

\section{Introduction}

Light pollution is one of the utmost dominant but minimally understood anthropogenic impacts in the Earth's biosphere. Light pollution continues to be a major hazard to the rising human factor that contributes to the environmental crisis about our biological necessities as well as the preservation of life in different animal species. The effect of light pollution on natural environments is vital as anthropogenic light pollution is becoming 
more of a global issue. In developed countries, light pollution is typically caused by activities that occur over a large geographic area $^{(1)}$. The emergence of new infectious diseases has increased in the last decade, posing a serious threat to global public health and contributes significantly as a route for nocturnal animals such as bats and rodents ${ }^{(2)}$ as its diversity in the biological response to nature ${ }^{(3)}$. City lighting growth has been exponential in the last half-century. Light pollution disrupts ecosystems and may perform a major role in the waning of species $^{(4)}$

Modern human society has evolved the Earth to such a degree that the present geological era was already called Anthropocene ${ }^{(5)}$ being a human-influenced era based on its overpowering worldwide indication that has been altered by humans. Satellite imagery or the domain of remote sensing and night lights has grown considerably through the span of early 2000 , this increment in the amount and quality of space and ground-based sensors are capable of measuring low levels of light in the visible band. This advancement has already had a significant effect on the study of light pollution, which has increased the same way with remote sensing of night lights ${ }^{(6)}$.

Traditional streetlights such as Low-Pressure Sodium (LSP) lamps which have spectra with relatively narrow bands emitting an orange-based light, and High-Pressure Sodium (HPS) lamps with broad-spectrum producing a pinkish light with closely light emitted in the ultraviolet (UV) spectrum.

Light Emitting Diodes (LED) does not help in minimizing light emissions. People utilize the saved money from low-cost LEDs just to add more lighting, thus making the site brighter. LED also shows a significant problem with its strong blue component in its spectrum, as the light easily dispersed that affects the environment and public health. LED technology allows for selective spectral composition of light emission, which may result in a less appealing LED color spectrum to insects and bats which respond differently to $\operatorname{LED}^{(7)}$.

As of this time of writing, there are limited researches that show the negative impacts of anthropogenic impacts of light pollution in the environment ${ }^{(8)}$. Human There has been alterations in the use of lighting technology which led to the use of low-energy light forms and drifts towards the use of white light.

The primary cause of light pollution dispersion and intensity is the increasing number of human population and its corresponding urbanization ${ }^{(3,8-10)}$. Exposure to light pollution influences ecological relationships ${ }^{(11)}$ throughout a wide variety of taxa and has detrimental effects on activities such as hunting, species breeding, and interactions ${ }^{(12)}$.

Bats are among those nocturnal species that are prone to be impacted by light pollution ${ }^{(13)}$ among the wide range of taxa. Bats constitute a significant influence on global biodiversity ${ }^{(5)}$ and conservation ${ }^{(14)}$ which post as the second most species-rich mammalian order in the world ${ }^{(6)}$.

Light pollution can have an influence upon a quantity of bat activities, including foraging and switching, onset, roosting, breeding, and hibernation. A study on the relationship between artificial light and bats shows that insect-related concerns since they are the primary food source of bats, the more light pollution, the more insects are being diverted, as well as bats ${ }^{(15,16)}$. The intensity of artificial light imposes interference of transit routes that may cause bats to use different routes to reach their foraging grounds. Bats leave their roosts when bat colonies experience alternative routes due to the presence of light pollution. Evidence advocates that the impact of lighting on bats ${ }^{(13)}$ is likely to cascade to the community level wherein it also alters the insect prey of bats.

It also discloses that dark interior sites have the most bat activities than at either light or dark forest edges ${ }^{(15)}$ and verifies that dark forest is vital for the insistence of several insectivorous bats ${ }^{(12,13,15)}$. Nearly a quarter of bat species are potentially at risk and have pressure on habitat from rising human populations is the primary key threatening their population ${ }^{(12)}$.

The Philippines has more than 7,100 islands that host over 70 bat species belonging to seven families ${ }^{(5)}$. Nearly $40 \%$ of the bat species in the Philippines are frugivorous or nectarivorous and the rest is mostly insectivorous ${ }^{(14)}$. A huge part of Philippine bats depends on primary forests.

In Mindanao, most research on forest bats is concentrated in the northern part of Mindanao. Mindanao has 53 species of bats, $32 \%$ of which are frugivorous and the rest are insectivorous ${ }^{(14)}$. There is also identified CoV in bats from Mindanao which supports the role of Philippine bats as a reservoir for the betacoronaviruses gene pool and emphasizes that potential zoonotic outbreaks via bat-animal or human encounters need to be regulated by protecting natural habitats ${ }^{(17)}$.

Bats presents ecological indicators illustrating the impact of environmental degradation on particular ecological processes that are vital to the functioning of the ecosystem are also attributed to the high diversity of bats ${ }^{(18)}$.

\section{Materials and Methods}

\subsection{Data Collection}

This study utilizes satellite imagery data to provide evidence of increasing light pollution radiance in Mindanao, Philippines. Satellite data images and radiance data $\left(10^{-9} \mathrm{~W} / \mathrm{cm}^{2 \star} \mathrm{sr}\right)$ from Visible Infrared Imaging Radiometer Suite (VIIRS) were processed 
using different Python codes to identify the extent of light pollution radiance in Mindanao from 2012 -2019. VIIRS data were set at an overlay of 60 transparency levels thru Sky Quality Meter (SQM) at 85 transparency levels for a hybrid base map at an altitude of $100 \mathrm{~km}$ to cover at least the whole of Mindanao. Figure $2 \mathrm{on}$-sets were taken from the Google Earth image to provide visualization on the exact location of Mindanao, and Figure 1. Showing the visible mountains as evidence of the presence of rich habitat for bats.

\subsection{Data Processing}

Data were processed using Python programming to evaluate the pixels as light pollution. Statistical analysis was performed using SPSS version 24 to determine the value of R-squared. In the light spectrum of LPS lamps, HPS lamps, and LED light. It reveals that LED has a strong blue light component in its spectrum which scatters easily and affects the environment. Also, it is noticeable that LEDs have a broader spectrum than that of LPS and HPS lamps.

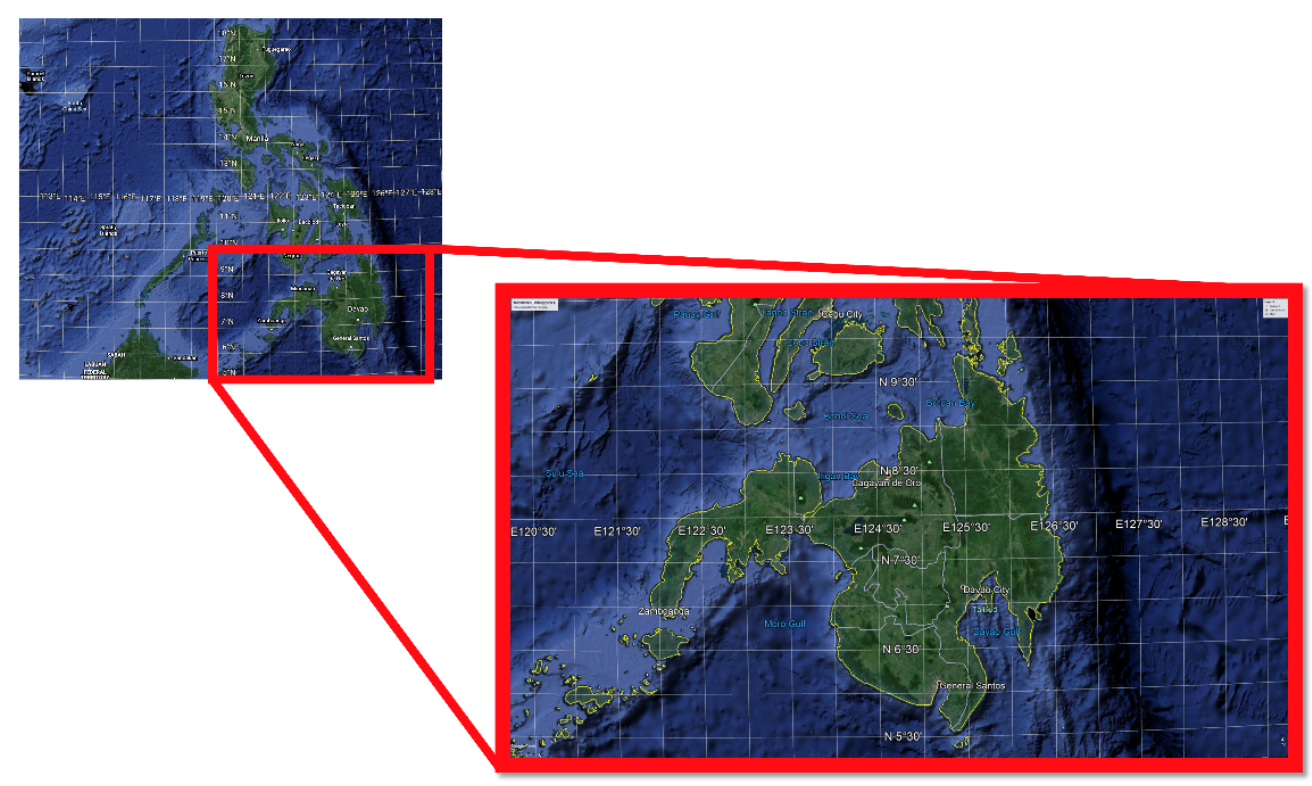

Fig 1. Geographic Location of Mindanao, Philippines

\subsection{Data Site}

Figure 1 displays the map of the Philippines, in which Mindanao is located at the southern part of the Philippine archipelago, the geographic location of Mindanao, Philippines at a latitude of $8 \mathrm{~N}$ and a longitude of 125E both were captured from Google Earth database. Mindanao is located in the southern part of the country and is one of the three island groups of the Philippine Archipelago. The perimeter spreads to $471 \mathrm{~km}$ north to south and $521 \mathrm{~km}$ east to west which comprises the $97,530 \mathrm{~km}^{2}$ land area. It is surrounded by Sulu and Cotabato Trench, Philippine Fault at its eastern side as well as the Philippine Trench.

It has a total population of $24,135,775$ as of the 2015 census which embodies about $24 \%$ of the Philippine population. It is a broad landscape comprised of six (6) Philippine regions with sixteen (16) provinces, thirty-three (33) cities, and four hundred twenty-two (422) municipalities. Rugged, faulted mountains and volcanoes occur in many areas. Mt. Apo is the country's highest peak with an elevation of 2,954 $\mathrm{m}$ and is an active volcano located at the southern part of the central highlands in Mindanao. Mindanao is formed by river systems, the famous Lake Lanao, other narrow coastal plains, bountiful basins, wide swamps, and a sanctuary for birds. The island has sufficient crops like corn, rice, bananas, the largest pineapple plantation, mangoes, and coconuts. Industries like timber, iron, nickel, gold, and coal deposits are some of the enterprises that uncover the fertile land.

\subsection{Statistical Analysis}

All pixel count of the yearly satellite image from 2012 to 2019 were processed using Python programming. The obtained data from python were analyzed using SPSS version 24 and Python codes were set into 95\% probability levels at $\mathrm{p}<0.05$. 


\section{Results and Discussion}

\subsection{Satellite Imagery Pixel Count}

Figure 2 shows the extent of light pollution in Mindanao from 2012 to 2019. It reveals the corresponding increase and spread of pixels as light pollution in the region from 2012 to 2019.
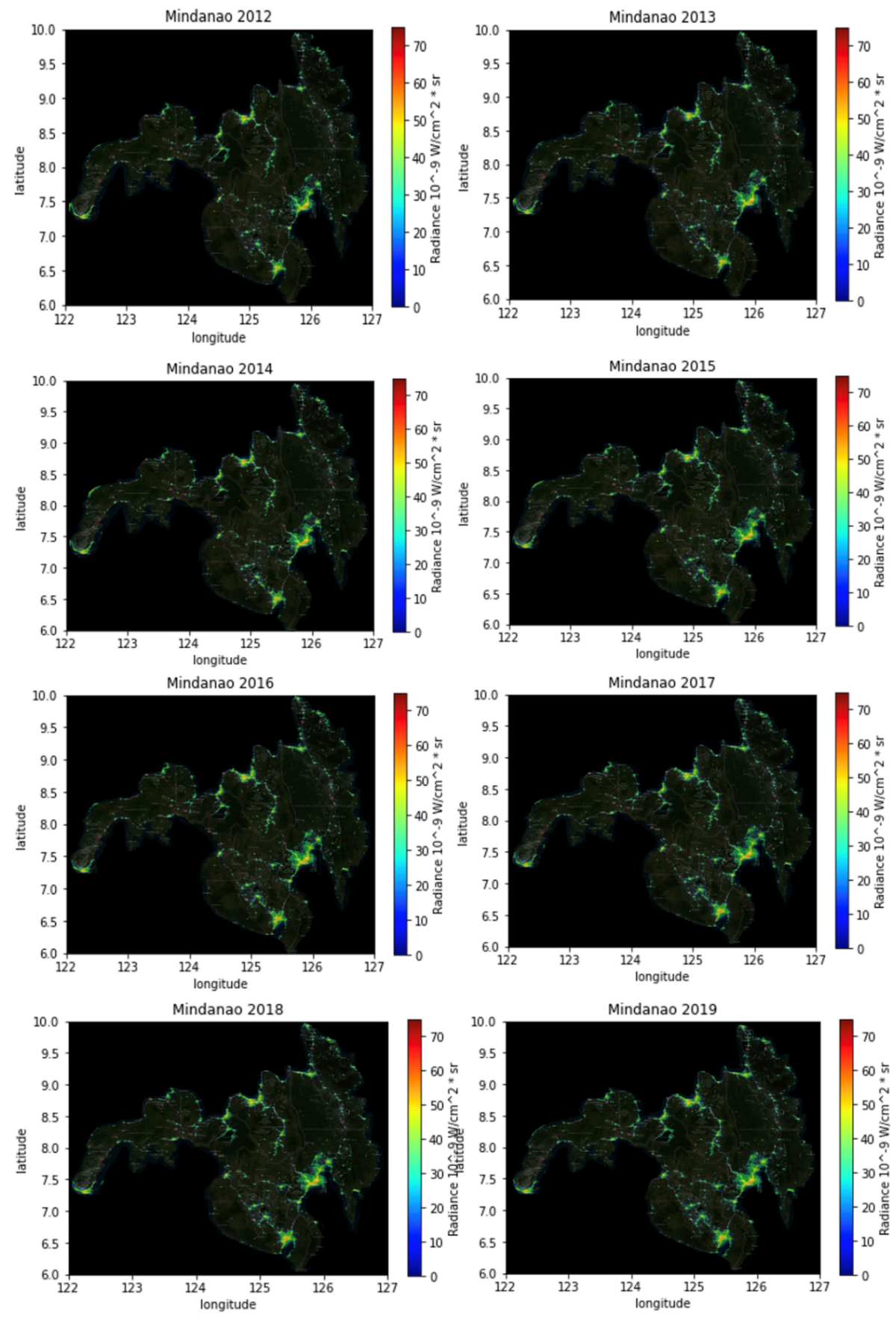

Fig 2. Light Pollution in Mindanao from 2012 to 2019 (image creditJurij Stare, www.lightpollutionmap.info, Earth Observation Group, NOAA National Geophysical Data Center) 


\subsection{Spread of Light Pollution}

The combined image of the Mindanao light pollution comparison from 2012 to 2019 as shown in Figure 3. The prominent and visible changes in light pollution dispersion were encircled from numbers 1 to 12 . It can be noticed that the amount of dispersion can be seen visually.

Cluster 1 from 2012 shows the part of Zamboanga wherein it displays the presence of red pixels in 2019. Cluster 2 is from the city of Pagadian, wherein green pixels were scattered in 2019. Cluster 3 is the town of Bacolod and Tubod, from the image in 2012 , it can be seen that the two were partly separated from each other, while as 2019 image presents, it shows that pixel images were going to bound to each other, thus a presence of light amplification between the two towns are being overlayed.

Cluster 4 Cagayan de Oro City is predominating evidence of light pollution as it stretches to the town of Malaybalay is being seen with intensifying green pixels. Butuan City is in Cluster 5, 2012 the presence of light pollution pixels concentrated in Butuan City, as time drives by, it reaches out to Buenavista to Nasipit, to Carmen. Cluster 6 is at the foot of the mountainous part of Maramag, in 2012 few spots were identified, while in 2019 Maramag pixels reach out to Malaybalay, which also sees the connection to Cluster 4 in Cagayan de Oro.
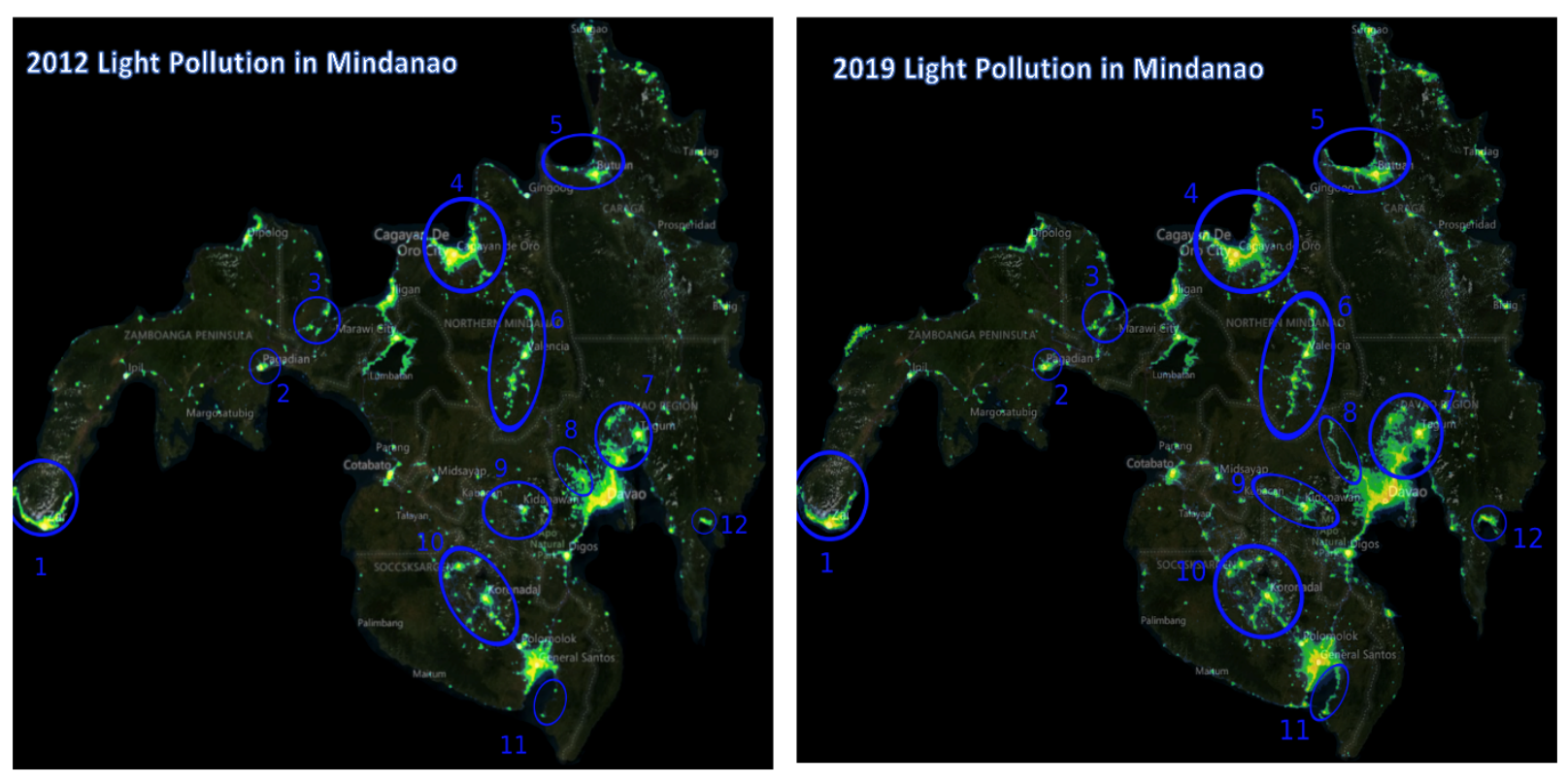

Fig 3. Comparison of Light Pollution in Mindanao from 2012 (left) to 2019 (right)

Cluster 7 showcases the part of Tagum, in 2012 few pixels were seen, then it shows sporadic pixel spread extending to the northwestern part and connecting the presence of light pollution towards Davao. The part of Calinan is classified in Cluster 8 and evident in 2019 that it extends and reaches going to the part of Maramag. In Kidapawan, few pixels are shown in 2012 but in 2019 it emerges new pixels and is being seen to be connecting to Digos City. Cluster 10 is the City of Koronadal, few pixels were recognized during 2012, light pollution shown has irregularly spread towards 2019 reaching General Santos City which is in Cluster 11. One of the prominent features in Mindanao is located in Mati, wherein in 2012 there were almost no pixels identified, however as it goes to 2019, pixels were very present throughout its parameters, and is anticipated that the site shows possible progress towards the community.

\subsection{Pixel Count of RGB}

Figure 4 displays the light pollution RGB pixel count in Mindanao from 2012 to 2019. The lines represent the red, green, and blue pixels identified by the satellite image processed by the program. Since the pale light pollution is represented by the color 
blue with a range of 0.15 to $0.50 \times 10^{-9} \mathrm{~W} / \mathrm{cm}^{2 *} \mathrm{sr}$, it is shown that blue pixels from the images are increasing from 2017 to 2019 , the brightness level in the area from 1 to $8 \%$ above the natural light $\left(1.7\right.$ to $\left.14 \mu \mathrm{cd} / \mathrm{m}^{2}\right)$. This indicates that parcels of land have availed lighting services in the region.
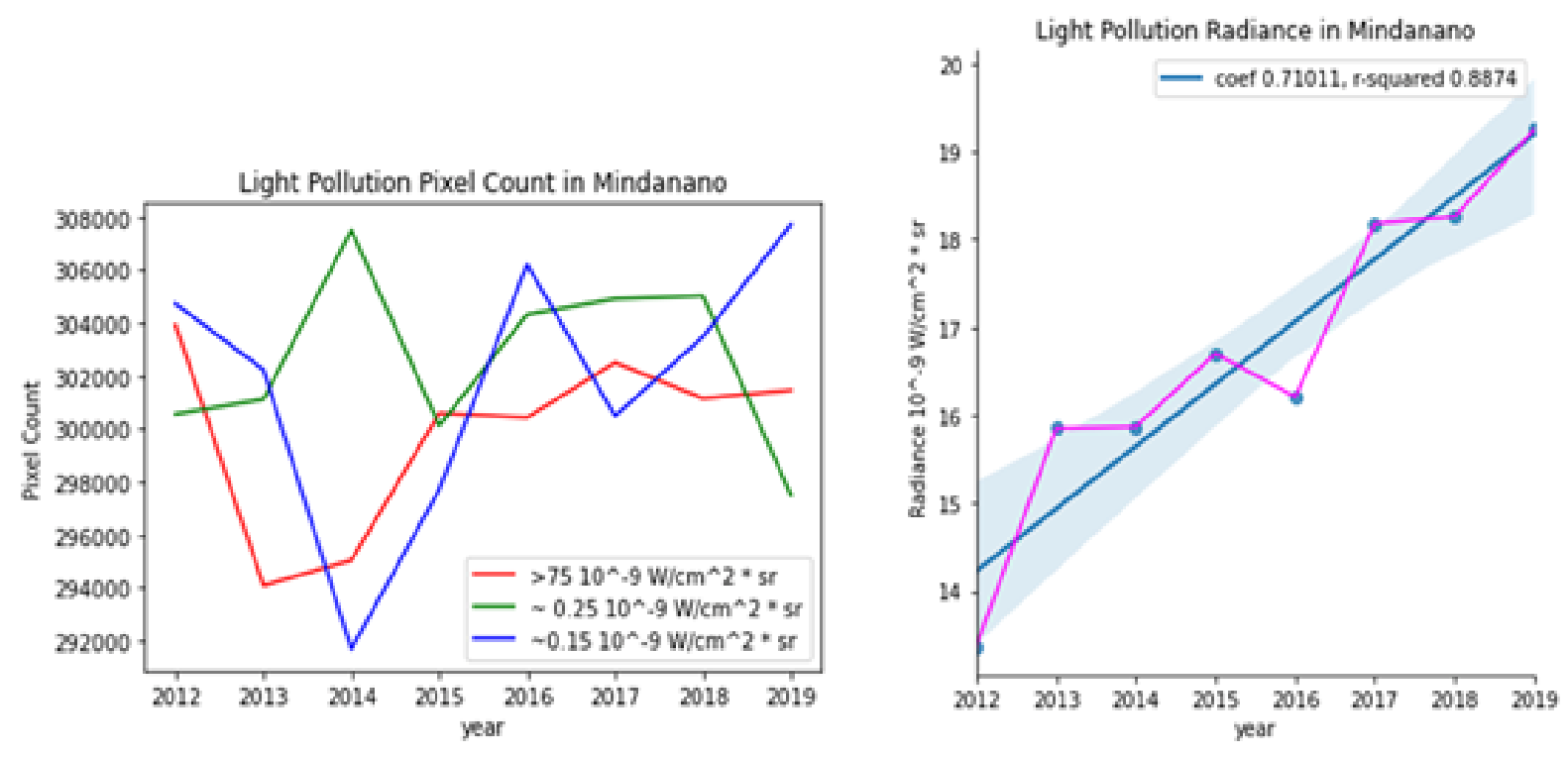

Fig 4. RGB Pixel Count (left) and Light Pollution Radiance in Mindanao (right)

The green pixel which ranges from 0.5 to $10 \times 10^{-9} \mathrm{~W} / \mathrm{cm}^{2 \star} \mathrm{sr}$ expresses a decline from 2018 to 2019 , the brightness level in the area with green pixels is from 8 to $50 \%$ above natural nighttime brightness $\left(14\right.$ to $87 \mu \mathrm{cd} / \mathrm{m}^{2}$ ). The red pixels identified in the satellite image poses a high nighttime light intensity (688 to $300 \mu \mathrm{cd} / \mathrm{m}^{2}$ ) with more than $5010^{-9} \mathrm{~W} / \mathrm{cm}^{2 \star} \mathrm{sr}$.

\subsection{Light Pollution Radiance Value}

Figure 4 also reveals the amount of radiance present in Mindanao from 2012 to 2019. The satellite images that represent radiance values do not resemble equal brightness for HPS and LED sources. It shows the increasing radiance throughout the region at present $19.25 \times 10^{-9} \mathrm{~W} / \mathrm{cm}^{2 *} \mathrm{sr}$, it implies the extreme dispersion on the amount of light being emitted from the ground. With a linear regression coefficient of 0.71011 and $\mathrm{R}^{2}$ value of 0.8874 having a strong positive linear relationship which indicates that as time goes by, the spread of light pollution and radiance also increases.

\section{Conclusion}

Bats are therefore critical to the functioning of the ecosystem and should be included in conservation plans aimed at preserving the integrity of the ecosystems. Habitat modifications affect the quantity, quality, and interconnection of foraging, drinking, and nesting sites available to bats. To conclude, Mindanao, Philippines has reported the detection of a bat betacoronavirus. With the reports presented in this study, it has been found out that the presence of light pollution in an area can influence the migration of bats which can lead to possible dispersal of bat species due to obliteration of their natural habitat and substantially through the identified extent of light pollution in the region. This study fosters evidence on the increasing light pollution in a bat-prone region thus, can conclude that light pollution might cause possible dispersal of bats related to BtCoV present in Mindanao, Philippines. Future research should also express considerations to prevent any outbreak or transmissions particularly bats that carry an array of viruses capable of infecting humans and other species. Moreover, this study would like to recommend that there should be set guidelines in protecting and conserving natural habitats to restrict bat-animal or bat-human encounters to avoid more viral host transfer. 


\section{Acknowledgement}

This paper is supported by the Center for Astronomy Research \& Development under the Science for Change Program of the Philippine's Department of Science and Technology - Philippine Council for Innovation, Energy, and Emerging Technology Research \& Development.

\section{References}

1) Lacoeuilhe A, Machon N, Julien JF, Bocq AL, Kerbiriou C. The Influence of Low Intensities of Light Pollution on Bat Communities in a Semi-Natural Context. PLoS ONE. 2014;9(10):e103042. Available from: https://dx.doi.org/10.1371/journal.pone.0103042.

2) Khan ZA, Yumnamcha T, Mondal G, Devi SD, Rajiv C, Labala RK, et al. Artificial Light at Night (ALAN): A Potential Anthropogenic Component for the COVID-19 and HCoVs Outbreak. Frontiers in Endocrinology. 2020;11:1-15. Available from: https://dx.doi.org/10.3389/fendo.2020.00622.

3) Davies TW, McKee D, Fishwick J, Tidau S, Smyth T. Biologically important artificial light at night on the seafloor. Scientific Reports. 2020;10(1). Available from: https://dx.doi.org/10.1038/s41598-020-69461-6.

4) Zissis G. Sustainable Lighting and Light Pollution: A Critical Issue for the Present Generation, a Challenge to the Future. Sustainability. 2020;12(11). Available from: https://dx.doi.org/10.3390/su12114552.

5) Tanalgo KC, Hughes AC. Priority-setting for Philippine bats using practical approach to guide effective species conservation and policy-making in the Anthropocene. Hystrix the Italian Journal of Mammalogy. 2019;30(1):74-83. Available from: https://doi.org/10.4404/hystrix-00172-2019.

6) Levin N, Kyba CCM, Zhang Q, de Miguel AS, Román MO, Li X, et al. Remote sensing of night lights: A review and an outlook for the future. Remote Sensing of Environment. 2020;237. Available from: https://dx.doi.org/10.1016/j.rse.2019.111443.

7) Bolliger J, Hennet T, Wermelinger B, Blum S, Haller J, Obrist MK. Low impact of two LED colors on nocturnal insect abundance and bat activity in a peri-urban environment. Journal of Insect Conservation. 2020;24(4):625-635. Available from: https://dx.doi.org/10.1007/s10841-020-00235-1.

8) Tamir R, Lerner A, Haspel C, Dubinsky Z, Iluz D. The spectral and spatial distribution of light pollution in the waters of the northern Gulf of Aqaba (Eilat). Scientific Reports. 2017;7(1):1-10. Available from: https://dx.doi.org/10.1038/srep42329.

9) de Miguel AS, Kyba CCM, Zamorano J, Gallego J, Gaston KJ. The nature of the diffuse light near cities detected in nighttime satellite imagery. Scientific Reports. 2020;10(1):1-16. Available from: https://dx.doi.org/10.1038/s41598-020-64673-2.

10) Bennie J, Davies TW, Duffy JP, Inger R, Gaston KJ. Contrasting trends in light pollution across Europe based on satellite observed night time lights. Scientific Reports. 2015;4(1):1-6. Available from: https://dx.doi.org/10.1038/srep03789.

11) Operti FG, Oliveira EA, Carmona HA, Machado JC, Andrade JS. The light pollution as a surrogate for urban population of the US cities. Physica A: Statistical Mechanics and its Applications. 2018;492:1088-1096. Available from: https://dx.doi.org/10.1016/j.physa.2017.11.039.

12) Garratt MJ, Jenkins SR, Davies TW. Mapping the consequences of artificial light at night for intertidal ecosystems. Science of The Total Environment. 2019;691:760-768. Available from: https://dx.doi.org/10.1016/j.scitotenv.2019.07.156.

13) Stone EL, Harris S, Jones G. Impacts of artificial lighting on bats: a review of challenges and solutions. Mammalian Biology. 2015;80(3):213-219. Available from: https://dx.doi.org/10.1016/j.mambio.2015.02.004.

14) Straka TM. Tree Cover Mediates the Effect of Artificial Light on Urban Bats. Frontiers in Ecology and Evolution. 2019;7:1-11. Available from: https://doi.org/10.3389/fevo.2019.00091.

15) Tanalgo KC, Tabora JAG, Hughes AC. Bat cave vulnerability index (BCVI): A holistic rapid assessment tool to identify priorities for effective cave conservation in the tropics. Ecological Indicators. 2018;89:852-860. Available from: https://dx.doi.org/10.1016/j.ecolind.2017.11.064.

16) Haddock JK, Threlfall CG, Law B, Hochuli DF. Light pollution at the urban forest edge negatively impacts insectivorous bats. Biological Conservation. 2019;236:17-28. Available from: https://dx.doi.org/10.1016/j.biocon.2019.05.016.

17) Russo D, Ancillotto L. Sensitivity of bats to urbanization: a review. Mammalian Biology. 2015;80(3):205-212. Available from: https://dx.doi.org/10.1016/ j.mambio.2014.10.003.

18) Tampon NVT, Rabaya YMC, Malbog KMA, Burgos SC, Bacus MG, Jr KL, et al. First Molecular Evidence for Bat Betacoronavirus in Mindanao. Philippine Journal of Science. 2020;149(1):91-94. Available from: https://philjournalsci.dost.gov.ph/images/pdf/pjs_pdf/vol149no1/first_molecular_evidence_for_ bat_betacoronavirus_in_mindanao_.pdf. 